\title{
OPTIMAL ALLOCATION OF FINAL WASTE DISPOSAL SITES BASED ON PHYSICAL AND SOCIAL FACTORS
}

\author{
Myungjin NA ${ }^{1}$, Koji KURIHARA ${ }^{2}$ and Naokazu GION³ \\ ${ }^{1}$ Graduate School of Environmental Science, Okayama University \\ (1-1,Tsushima-Naka, 3-chome, Okayama 700-8530, Japan) \\ E-mail:mjna@ems.Okayama-u.ac.jp \\ 2 Professor, Graduate School of Environmental Science, Okayama University \\ (1-1,Tsushima-Naka, 3-chome, Okayama 700-8530, Japan) \\ E-mail: kurihara@ems.Okayama-u.ac.jp \\ 3 Graduate School of Environmental Science, Okayama University \\ (1-1,Tsushima-Naka, 3-chome, Okayama 700-8530, Japan) \\ E-mail: gion@ems.Okayama-u.ac.jp
}

\begin{abstract}
Construction of final waste disposal sites has become increasingly difficult as the problem of their location has become an important issue. Final waste disposal sites have a negative image of fostering various kinds of pollution, increased traffic volume, noise by trucks and bulldozers, and aggravated living conditions. These concerns indicate that social factors, such as waste landfills' public image, must be considered along with physical factors when locating the final waste disposal sites.

This paper presents a method for determining an optimal site from the two perspectives of physical and social factors. First, we estimate spatial distribution for physical factors using various costs for waste disposal and land prices. Secondly, using results of a survey, we investigate the relationship between cognition of final waste disposal site and age group as covariates and estimate spatial distribution for social factors from the spatial distribution for the age group.
\end{abstract}

Key Words : optimal location, physical factor, social factor, spatial distribution

\section{INTRODUCTION}

Some wastes are recycled for creating a recycling society these days, but most remain buried in the ground or burned. In other words, construction of final waste disposal sites can not be avoided. Such sites are sometimes called landfills. However, landfill areas become unusable for most socially beneficial uses after they close. Even though some closed landfills have been converted into recreational areas, landfills are typically unsuitable for urban, commercial or industrial development, or agricultural use. Landfills are permanent facilities that impart risks to the environment and public health. They must therefore be monitored and maintained for many decades after their closure. Consequently, both physical factors such as costs and social factors such as the public landfill image must be investigated simultaneously when building landfills that residents might oppose. However, no practical studies that consider both physical and social factors have been reported in the literature.

Therefore, it is generally impossible to treat the target function merely with one variable such as a cost or ratio, as historical methods have done. An accompanying difficulty pertains: expressing consciousness and attitudes of residents as one variable. Another problem is the expression of spatial distribution and structure. This paper describes a methodology to quantify social factors such as the consciousness and attitudes of residents and estimates a spatial distribution based on it.

Optimal location based on sites' physical factors is considered using a waste management network that 
is calculated from the 'waste management flow chart' prepared by the Ministry of the Environment. For analysis of social factors, data have been obtained from surveys about landfills. Relationships between attitudes of residents and age groups as a covariate are investigated through covariance structure analyses, and spatial distribution according to social factors is estimated using the spatial distribution of the age group.

\section{OVERVIEW OF THE SITING PROCESS APPLIED TO FINAL WASTE DISPOSAL SITES}

Determining the location of a final waste disposal site is an important component of the waste-management process. Inappropriate location of a site can engender environmental damage, social and political conflict, and economic inefficiency. The process of locating sites for waste facilities has been investigated widely. Different methods have been created over the last few decades to assist in developing more efficient waste disposal siting.

Conventional location and siting models for waste management of the late 1960s emphasized financial optimization. Esmali4) and Helms and Clark $^{5)}$ are examples. Those models assessed the best location for waste facilities considering several limited and previously known location options. Different combinations of facilities (usually landfill and incineration) and their locations are then compared according to their respective costs.

During the 1980s, awareness of the potential of pollution of waste disposal engendered more restrictive environmental regulations for the location, implementation and operation of waste facilities. Moreover, emphasis upon material recycling has gradually changed the orientation of system analysis of waste management.

In the late 1980s and 1990s, conventional waste models of the previous decade began to include waste recovery facilities and assumptions of waste reduction. The optimizing function was generally based on economic analyses, with the difference that revenues from waste recovery and environmental costs of pollution were included. Jacobs and Everett $\left.{ }^{6}\right)$ and Lund ${ }^{11)}$, for example, developed models that schedule landfills and waste recovery activities according to minimization of the net present value of the discounted costs that accrue during the landfill's lifetime.

According to a state-of-the-art review on waste management models developed by McDonald ${ }^{13)}$, Chang was the first to incorporate environmental costs explicitly2).
A model developed by Daskalopoulos, Badr, and Probert ${ }^{3)}$ identifies the optimal combination of technologies for the handling, treatment, and disposal of municipal wastes according to economic and environmental criteria.

Geographical approaches to waste facility location have been developed since the early 1980s. Geographic information systems are widely used to generate suitability maps. The capabilities of GIS for storage, retrieval and manipulation of spatial data, as well as of visualization of outputs, greatly improve the performance of such approaches.

Early studies, such as that developed by Lane and McDonald ${ }^{7}$, merely considered sites' environmental properties. During the 1990s, however, social and economic criteria were integrated into GIS analyses. Lober ${ }^{10)}$, for example, addressed the not in my backyard (NIMBY) phenomenon, which typifies the increasing community opposition to facility siting. Siddiqui, Everett, and Vieux ${ }^{15}$ ) developed a methodology to determine the best locations for siting landfills by integrating GIS and analytical hierarchical processes (AHPs). Leão, Bishop, and Evans ${ }^{8)}$ presented a model to model the demand for and location of facilities for waste disposal both spatially and dynamically. That developed model consists of a loosely coupled system that integrates GIS and cellular automata (CA) to give it spatial and dynamic capabilities.

Most existing models, however, as briefly reviewed in this section, do not address social factors when locating the final waste disposal site.

\section{METHODOLOGY}

The study was performed with a final waste disposal site in Okayama Prefecture. In the case of optimal location based on physical factors, target functions for optimal location were acquired using the shortest distance from resource to landfill, land prices, and transport costs, after estimating spatial distribution by expressing geographic areas by $10 \mathrm{~km}$ mesh, the site that its value was smallest was selected as the optimal location. This analysis, based on the physical factors, was performed easily using the network ability of GIS.

For optimal location that is based on social factors that were not treated in existing studies, spatial distribution was estimated using residents' attitudes about the landfill, as calculated from data that had been collected through surveys. The site for which the attitudes were most favorable was selected as the optimal location.

(1) Optimal location based on physical factors

The 'waste disposal flow chart' announced by the 
Ministry of the Environment in 2003 is shown in Fig.1. Optimal location is considered from this waste disposal network.

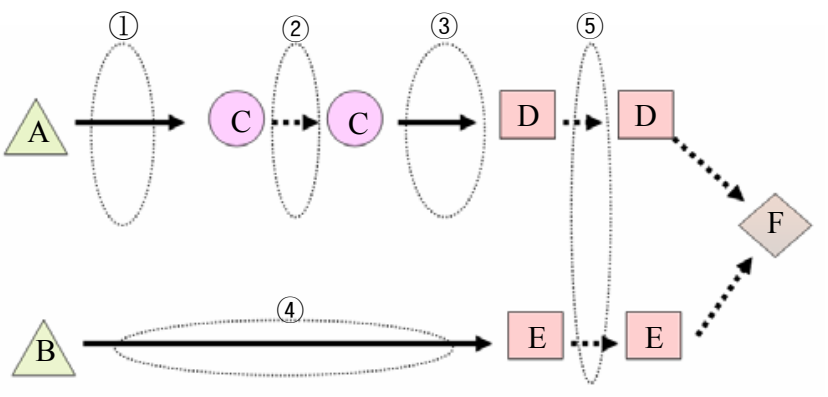

Fig.1 Waste disposal flow chart ${ }^{14)}$

In Fig.1, A, B is node of the amount of planned disposal of general waste; $\mathrm{C}$ is node of middle disposing facility; D, $\mathrm{E}$ is node of final disposal site; and $\mathrm{F}$ is hypothetical node. The dotted circles represent costs occurring at each point as follows: (1) is cost of transport of waste; (2) is cost of middle disposal; (3) is cost of transport of remainder waste; (4) is cost of direct transport of final disposal site; and (5) is cost of final disposal.

The waste disposal process was assumed to locate facilities optimally according to the following.

1) Only one kind of waste is used.

2) The target area is divided into two or more meshes.

3) Transport costs of waste are proportional to the volume of transport and the transport distance.

4) Remaining waste is produced at a fixed rate in an intermediate disposal facility; it is transported to the final disposal site.

5) The average cost of intermediate disposal is proportional to the amount of disposed waste.

6) The average cost of final disposal is proportional to the amount of disposed waste.

7) Some collected waste is transported directly to the final disposal site.

8) Remaining waste that is produced by intermediate disposal is eventually disposed of completely.

9) Waste that is produced at each place is disposed at the nearest disposal site.

10) Centers of each mesh are the representative locations of waste produced from each mesh data.

The total cost of waste disposal is calculated by adding cost of location for final disposal site to those costs. The equation is therefore
Totalcost $=(1)+(2)+(3)+(4)+(5)$

+ location cost for final disposal site

$$
\begin{aligned}
= & \sum_{a \in A t_{1}} d x_{a} \cdot T C_{a}+\sum_{a \in A r} d x_{a} \cdot R M C_{a} \\
& +\sum_{a \in A t_{2}} d \cdot r \cdot x_{a} \cdot T C_{a}+\sum_{a \in A t_{3}}(1-d) x_{a} \cdot T C_{a} \\
& +\sum_{a \in A d} x_{a}\{1+d(r-1)\} D M C_{a}+\sum_{i} T P_{i} \cdot \delta_{i}
\end{aligned}
$$

Therein, the relevant variables respectively denote the following.

$a:$ the link number

$x_{a}$ : the amount of planned collection at each zone

(ton)

$C:$ the transport cost per unit distance (yen/ton)

$l_{a}$ : the distance of transport link $a(\mathrm{~km})$ (as direct distance)

$T C_{a}=C \cdot l_{a}:$ the cost per ton of the transport link of waste (yen/ton)

$d$ : the rate at which intermediate disposal is performed from the amount of planned collection $(0 \leq d \leq 1)$ (exogenous value)

$r$ : the rate at which waste is reduced by intermediate disposal $(0 \leq r \leq 1)$ (exogenous value)

$R M C_{a}$ : the cost per ton of the link of intermediate disposal activity (yen/ton)

$D M C_{a}$ : the cost per ton of the link of final disposal activity (yen/ton)

$T P_{i}$ : the land price of mesh $i$ (yen)

$\delta_{i}$ : a dummy variable. 1 when final disposal facility is located in mesh $i$, otherwise 0

$A t_{1}$ : the subset of the link of waste transport from the zone in which waste is produced to the intermediate disposal facility

$A t_{2}$ : the subset of the link of waste transport from the intermediate disposal facility to the final disposal facility

$A t_{3}$ : the subset of the link of waste transport from the zone in which waste is produced to the final disposal facility

$A r$ : the subset of the link of intermediate disposal activity

Ad : the subset of the link of final disposal activity

The costs of waste disposal at each mesh that were calculated using information of the existing final disposal site and the amount of waste disposal in 
Okayama Prefecture by eq.(1) is shown in Fig.2. The blue points show existing final disposal sites; white points are intermediate disposal sites. Fig. 2 shows that the costs are high concomitant with the color depth. The map information was provided from following website, http://gisplaza.stat.go.jp/GISPlaza. The points project the center of each mesh using Arcview with latitude and longitude as final disposal site, middle disposal site, and proposed area of final disposal site.

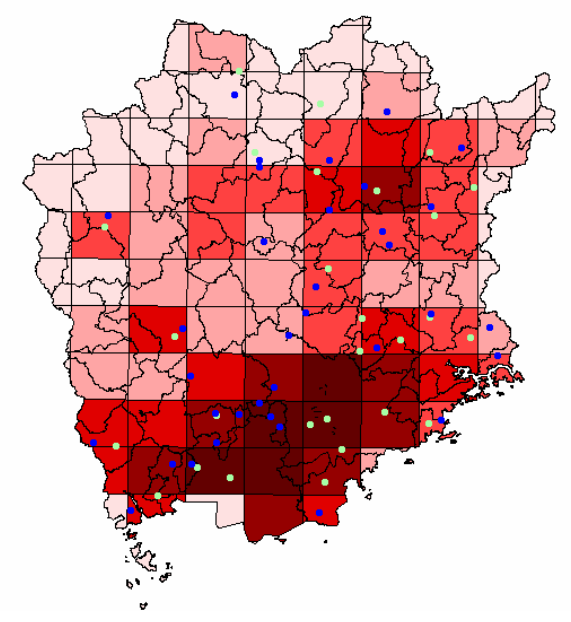

Fig.2 Spatial distribution based on costs of waste disposal in Okayama Prefecture.

If a new final disposal site is constructed, the area that minimizes the sum of three variables (i.e. transport cost of remaining waste, direct transport cost of final disposal, and the cost for locating the final disposal site facility) in eq.(1) will be selected as that optimal site. Other variables in eq.(1) do not change greatly according to location. Therefore, they were excepted from the equation. That is, the target function is

$$
\begin{aligned}
Z= & \sum_{a \in A t_{2}} d \cdot r \cdot x_{a} \cdot T C_{a} \\
& +\sum_{a \in A t_{3}}(1-d) x_{a} \cdot T C_{a}+\sum_{i} T P_{i} \cdot \delta_{i}
\end{aligned}
$$

The optimal final waste disposal site is determined by the area that has the smallest $Z$ value of the target function.

\section{(2) Data collected for analyzing social factors}

Data were collected through a survey for Saitama Prefecture residents because no similar survey was conducted with residents of Okayama Prefecture.
Table 1 Items and questions used for covariance structure

\begin{tabular}{|c|c|}
\hline Item & Question \\
\hline Landfill visit & $\begin{array}{l}\text { I have [visited/ not visited / } \\
\text { ever seen by newspaper or } \\
\text { television about] landfill. }\end{array}$ \\
\hline $\begin{array}{l}\text { Awareness of } \\
\text { landfill existence }\end{array}$ & $\begin{array}{l}\text { I [know/ don't know] where } \\
\text { the landfill is in municipality. }\end{array}$ \\
\hline $\begin{array}{l}\text { Awareness of } \\
\text { use of the land } \\
\text { after the landfill }\end{array}$ & $\begin{array}{l}\text { I [know/ don't know] that land } \\
\text { is being used after landfill } \\
\text { operations cease. }\end{array}$ \\
\hline $\begin{array}{l}\text { Necessity of } \\
\text { landfill }\end{array}$ & $\begin{array}{l}\text { I thing that landfill is } \\
\text { [necessary/ not necessary]. }\end{array}$ \\
\hline $\begin{array}{l}\text { Pros and cons } \\
\text { of landfill } \\
\text { construction }\end{array}$ & $\begin{array}{l}\text { If landfill is built near from my } \\
\text { house, I will [agree/ oppose/ } \\
\text { not mind]. }\end{array}$ \\
\hline
\end{tabular}
analysis.

Table 2 Recoding of collected data.

\begin{tabular}{|ll|}
\hline \multicolumn{1}{|c|}{ Observed value } & \multicolumn{1}{c|}{ Recoding } \\
\hline Landfill visit & $\begin{array}{l}\text { 2=visited, } 1=\text { ever seen by new } \\
\text { spaper or television about, } \\
0=\text { not visited } \\
1=\text { know, } 0=\text { don't know }\end{array}$ \\
$\begin{array}{l}\text { Awareness of } \\
\text { landfill existence }\end{array}$ & \\
$\begin{array}{l}\text { Awareness of use } \\
\text { of the land after } \\
\text { the landfill }\end{array}$ & $1=$ know, $0=$ don't know \\
$\begin{array}{l}\text { Necessity of } \\
\text { landfill }\end{array}$ & $1=$ necessary, $0=$ not necessary \\
$\begin{array}{l}\text { Pros and cons } \\
\text { of landfill } \\
\text { construction }\end{array}$ & $\begin{array}{l}2=\text { agree, } 1=\text { not mind, } \\
0=\text { oppose }\end{array}$ \\
\hline
\end{tabular}

To improve recycling rate of waste, the Center of Environmental Science in Saitama Prefecture conducted the attitude survey in separate collection of recycled waste. This was two surveys that named as 'The questionnaire about recycling waste' and 'The questionnaire about landfill'. The survey sheet was directly handed out, and taken back by mail. The total number of distribution was 1230 , the number of responses was 430 , and the proportion of response was about $35 \%$. As age composition of respondents, less than 9 was $1 \%, 20-29$ was $6.5 \%, 30-39$ was $8.4 \%, 40-49$ was $7.5 \%, 50-59$ was $11.8 \%, 60-69$ was $51.0 \%, 70-79$ was $13.2 \%$, and more than 80 was $0.7 \%$. It resulted that old generations covered $65 \%$ of total respondents because of many responses from more than 60. As gender composition, the male was $46.3 \%$, and the female was $53.7 \% 16$. The questionnaire about landfill that was used this study was composed of household composition (i.e., gender, age, residence) and nine questions relative to landfill. Items that used for covariance structure analysis in those are shown in Table 1.

The Data which had been collected from Saitama Prefecture was for analyzing (Table 2). 
The collected data were used to quantify landfill attitude by age group. The quantified landfill attitude's values were used to estimate spatial distribution of landfill attitude in Okayama Prefecture on the assumption that the whole country is similar structure of consciousness.

\section{(3) Covariance structure analysis}

The results of survey are used to analyze social factors. However, it can be various results according to an analysis intention or method. We have analyzed using covariance structure analysis of statistical method to understand the landfill attitudes of residents.

First, factor structure was explored using exploratory factor analyses. Factor analysis is original idea of latent variable in covariance structure analysis. The factor is estimated indirectly from data that can be observed, because it can't be measured directly. Exploratory factor analysis does not assume relationship between observed variables and latent variables in advance, but explores it from calculation results. This method uses a fixed model that assumes that all factors are related to observed variables after determining the number of factors in the beginning of the calculation. In case of this study, exploratory factor analysis was used to explore relationship between observed variable (i.e., landfill visit, awareness of landfill existence, awareness of use of the land after the landfill, necessity of landfill, and pros and cons of landfill construction) and latent variable.

Table 3 Results of the exploratory factor analysis.

\begin{tabular}{|lcc|}
\hline & \multicolumn{2}{c|}{ Factors } \\
\cline { 2 - 3 } & 1 & 2 \\
\hline Awareness of landfill & 0.5981 & 0.1060 \\
existence & 0.5672 & 0.0073 \\
Landfill visit & 0.2415 & 0.1794 \\
$\begin{array}{l}\text { Awareness of use of } \\
\text { the land after the landfill }\end{array}$ & -0.0064 & 0.5310 \\
$\begin{array}{l}\text { Necessity of landfill } \\
\text { Pros and cons of landfill } \\
\text { construction }\end{array}$ & 0.1534 & 0.4518 \\
\hline
\end{tabular}

Two factors were extracted on the condition that their eigenvalues are greater than one, and the contribution rate was $54.36 \%$. The first factor included landfill visits, awareness of landfill existence, and awareness of land use after landfill operations cease. The second factor was necessity of the landfill, along with the pros and cons of landfill construction. The result is shown in Table 3.

We regards factor1 as awareness of landfill, and factor 2 as attitude of landfill construction.

A model was produced using covariance structure analysis of statistical method with this result to evaluate landfill attitudes of residents. That model is shown in Fig.3.

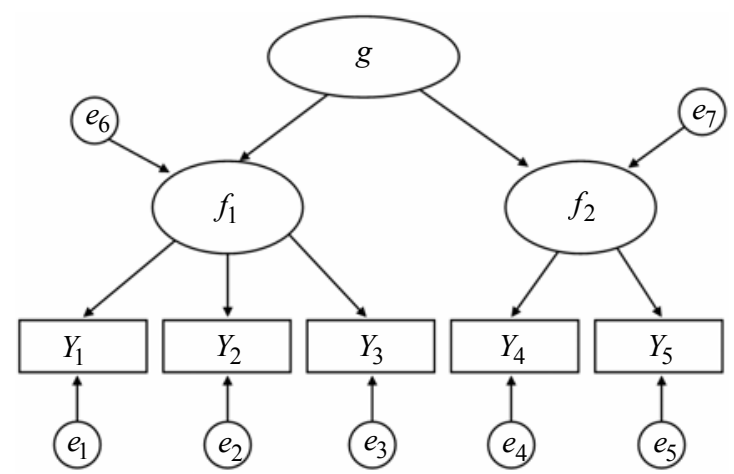

Fig.3 Model of covariance structure analysis to evaluate landfill attitudes.

Fig.3 depicts a model in which the landfill attitudes of residents influence the awareness of the landfill and the attitudes pertaining to landfill construction, awareness of landfill influence on the first factor, and the attitudes of landfill construction's influence on the second factor.

Formulation of this model is shown in eqs.(3) and (4).

$$
\begin{gathered}
{\left[\begin{array}{l}
Y_{1} \\
Y_{2} \\
Y_{3} \\
Y_{4} \\
Y_{5}
\end{array}\right]=\left[\begin{array}{ll}
\alpha_{1} & 0 \\
\alpha_{2} & 0 \\
\alpha_{3} & 0 \\
0 & \alpha_{4} \\
0 & \alpha_{5}
\end{array}\right]\left[\begin{array}{l}
f_{1} \\
f_{2}
\end{array}\right]+\left[\begin{array}{l}
e_{1} \\
e_{2} \\
e_{3} \\
e_{4} \\
e_{5}
\end{array}\right]} \\
{\left[\begin{array}{l}
f_{1} \\
f_{2}
\end{array}\right]=\left[\begin{array}{l}
\beta_{1} \\
\beta_{2}
\end{array}\right] g+\left[\begin{array}{l}
e_{6} \\
e_{7}
\end{array}\right]}
\end{gathered}
$$

Therein, $Y_{1}, Y_{2}, Y_{3}$ respectively denote landfill visits, awareness of landfill existence, and awareness of land use after the landfill; $Y_{4}, Y_{5}$ respectively represent the necessity of landfill, and pros and cons of landfill construction. Also, $f_{1}$ denotes landfill awareness; $f_{2}$ shows the attitudes related to landfill construction; $g$ is the landfill attitudes of residents; and $\alpha_{1}, \ldots, \alpha_{5}, \beta_{1}, \beta_{2}$ are path coefficients corresponding on paths, respectively. In addition, $e_{1}, \ldots, e_{7}$ are error terms.

If this model were expressed by a vector after substituting eq.(4) for eq.(3), then

$$
\mathbf{y}=\boldsymbol{\gamma} \cdot g+\mathbf{e}
$$


where $\boldsymbol{\gamma}$ is $\boldsymbol{\alpha} \boldsymbol{\beta}$ (where $\boldsymbol{\alpha}$ denotes the matrix of path coefficient in eq.(3) and $\boldsymbol{\beta}$ is the vector of path coefficient in eq.(4)). This study is intended also to incorporate the landfill attitudes of residents. Furthermore, $g$ can be estimated from eq.(5) using least-squares estimation. The estimating equation is shown in eq.(6).

$$
\hat{g}=\left(\boldsymbol{\gamma}^{T} \boldsymbol{\gamma}\right)^{-1} \boldsymbol{\gamma}^{T} \mathbf{y}
$$

\section{(4) Evaluating model}

Parameter is decided by minimizing error function using maximum likelihood estimation in covariance structure analysis. The error function is

$$
f_{\mathrm{ML}}=\operatorname{tr}\left(\boldsymbol{\Sigma}^{-1} \mathbf{S}\right)-\log \left|\boldsymbol{\Sigma}^{-1} \mathbf{S}\right|-k
$$

where $\boldsymbol{\Sigma}$ is variance-covariance matrix including parameter that is calculated from model, $\mathbf{S}$ is variance-covariance matrix that is obtained from observed variable, and $k$ is the number of observed variables. This $f_{\mathrm{ML}}$ is difference between model and actual data. This represents goodness of fit of a model for data. It means that goodness of fit is good that the value of $f_{\mathrm{ML}}$ is small. $\chi^{2}$ is used as criterion. The test statistic of this and degree of freedom are as follows.

$$
\chi^{2}=(n-1) f_{\mathrm{ML}}
$$

where $n$ is the number of data.

$$
d f=\frac{1}{2} k(k+1)-p
$$

where $p$ is the number of parameter. The null hypothesis is that relational model is right. follows.

GFI (Goodness of Fit Index) is defined as

$$
\mathrm{GFI}=1-\frac{\operatorname{tr}\left((\mathbf{W}(\mathbf{S}-\mathbf{\Sigma}))^{2}\right)}{\operatorname{tr}\left((\mathbf{W S})^{2}\right)}
$$

where $\mathbf{S}$ is actual variance-covariance matrix, $\boldsymbol{\Sigma}$ is variance-covariance matrix by model, $\mathbf{W}$ is weight matrix. If calculated value and actual value are completely equal, GFI becomes one.

The usual criteria of minimization are to minimize difference between observed data and model. However, the observed data is just sample. F0 is criterion measure of minimization between real population and model. But, F0 is affected parameter. That is, the complicated model which increased parameters is easy to be preferred to a reduced model. The criterion that revised this weak point is RMSEA (Root Mean Square Error of Approximation). RMSEA is defined as follows.

$$
\text { RMSEA }=\sqrt{\frac{\text { F0 }}{\text { degree of freedom }}}
$$

RMR (Root Mean square Residual) is defined as follows.

$$
\begin{aligned}
& \text { RMR } \\
& =\sqrt{\frac{\left(s_{x}^{2}-\sigma_{x}^{2}\right)^{2}+\left(s_{y}^{2}-\sigma_{y}^{2}\right)^{2}+\left(s_{x y}-\sigma_{x y}\right)^{2}+\cdots}{\frac{k(k+1)}{2}}}
\end{aligned}
$$

where variance and covariance of $\sigma$ indicate theoretical value measured from model, variance and covariance of $s$ indicate actual value from data, and $k$ is the number of observed variables. In this way, RMR represent average of difference between theoretical value and actual value about each variance-covariance.

The result of goodness of fit for model in Fig.3 is shown in Table 4.

Table 4 Results of goodness of fit for the model estimating the landfill attitudes of residents.

\begin{tabular}{|cccccc|}
\hline \multicolumn{3}{c}{$\chi^{2}$ test } & & & \\
\cline { 1 - 3 }$\chi^{2}$ value & df & p-value & GFI & RMSEA & RMR \\
\hline 4.9 & 4 & 0.2977 & 0.994 & 0.025 & 0.008 \\
\hline
\end{tabular}

The traditional chi-square fit test is assessed in Table 4. However, because it has been recognized as an inappropriate test for large sample size ${ }^{1), 12)}$, three other indexes are also include. Acceptable model fits are indicated by values of GFI greater than 0.90 , RMSEA values below 0.10 , and RMR values below 0.10 . Overall, the model fit was good. Consequently, this model was used to estimate the landfill attitudes of residents.

\section{(5) Optimal location based on social factors}

Covariance structure model by each age group was constructed from recoding data. Landfill attitude by age group was estimated using eq. (6) after estimating each parameter in each covariance structure model. The estimates are shown in Table 5. In this study, this landfill attitude was suggested as a index to measure landfill comprehension of residents. 
The landfill attitudes of residents of six age groups (i.e., $\leq 29,30-39,40-49,50-59,60-69,70$ $\geq$ ) were calculated using this model; the spatial distribution for social factors in Okayama Prefecture were estimated from

$$
I_{i}=\sum_{k=1}^{6} I_{k, i} \frac{p_{k, i}}{T_{i}}
$$

where $k$ is age group's number, $I_{i}$ denotes the lanfill attitudes in mesh $i, I_{k, i}$ is the landfill attitude of age group $k$ in mesh $i, P_{k, i}$ is the population of age group $k$ in mesh $i$, and $T_{i}$ is total population in mesh $i$. Eq. (13) is to estimate spatial distribution of landfill attitude in Okayama Prefecture using results from Table 5 that is calculated using survey in Saitama Prefecture. Consequently, the optimal final waste disposal site is determined by the area that has highest $I_{i}$.

\section{RESULTS}

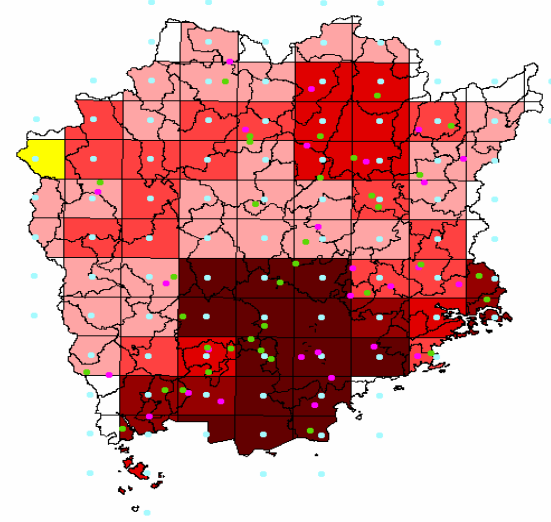

Fig.4 Spatial distribution based on $Z$ values of landfill attitudes by age group in Okayama Prefecture.

The results of estimated spatial distribution based on physical factors are depicted in Fig.4.

This figure is classified by color according to the $Z$ value of the target function when assuming that the final waste disposal site is built for every mesh. It shows the highest $Z$ value concomitant with the color depth. The yellow area shows the location where the value of $Z$ is lowest.

To locate optimally based on social factors, first, the landfill attitudes by age group were calculated. The result is shown in Table 5 .
Table 5 Landfill attitudes of residents by age group.

\begin{tabular}{|cc|}
\hline Age group & Landfill attitude \\
\hline$\leq 29$ & 0.531 \\
$30-39$ & 0.505 \\
$40-49$ & 0.588 \\
$50-59$ & 0.482 \\
$60-69$ & 0.852 \\
$70 \geq$ & 0.849 \\
\hline
\end{tabular}

The age group 60-69 and 70 $\geq$ had a higher degree of landfill comprehension than the others.

Spatial distributions estimated from the landfill attitudes by age group were calculated using eq.(13), as shown in Fig.5.

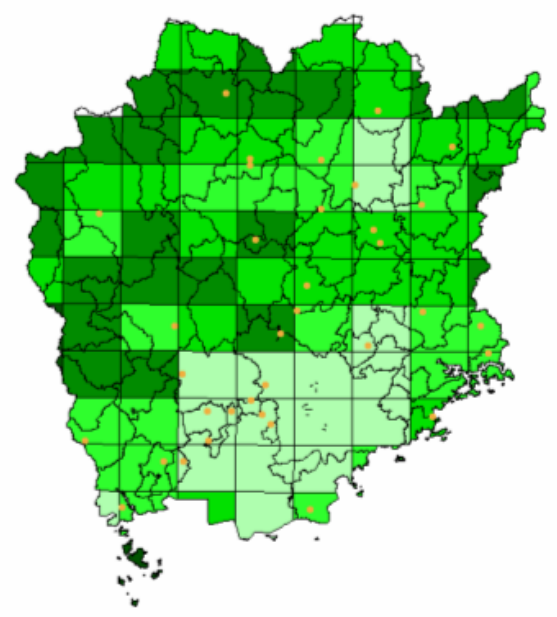

Fig.5 Spatial distribution based on $I_{i}$ values of landfill attitudes by age group in Okayama Prefecture.

Spatial distribution of landfill attitude in Okayama Prefecture was estimated using result from landfill attitude by age group that has been quantified using survey in Saitama Prefecture. Fig.5 represented by $I_{i}$ in eq. (13) depicts landfill attitudes that are higher for deeper colors. It is thought that a site which landfill attitude is high may have lower opposition of residents. Public opposition to the siting of hazardous waste management facilities, particularly landfills, is the most critical problem in developing new facilities ${ }^{9}$. Fig. 5 represents that sites which have higher landfill attitude are located on northwest of Okayama Prefecture. Consequently, to select area which has high landfill attitude can reduce probability of failure, when we locate site for a new landfill.

\section{CONCLUSION}

This paper presented a new methodology whereby a final waste disposal site is located 
optimally based on social factors such as the landfill attitudes and physical factors such as transport cost and disposal cost. The method presented here is the first attempt reported in the literature to deal with final waste disposal site location based on social factors. However, errors can occur according to regional differences because optimal location of final waste disposal sites in Okayama Prefecture was performed using results of surveys conducted in Saitama Prefecture. Moreover, accuracy of estimates might be low because age was considered only as a covariate in this study. It must be considered in relation to other various covariates to estimate the spatial distribution more exactly.

Physical and social factors must be considered simultaneously when determining the locations for final waste disposal sites. Future studies will require some method to link spatial distribution between physical and social factors.

Safety aspects must be also considered with physical and social factors. The regions that have landfills might be exposed to dangers through alteration and degradation of impermeable liners, leaching of contaminated water into groundwater following precipitation, and degradation of the disposal site by an earthquake. To investigate spatial distribution based on these safety requirements necessitates spatial distribution according to yearly rainfall, predicted earthquakes, and foundation strength.

The result of optimal location will be improved if physical factors, social factors, and safety aspects are examined together. To do so, multivariate spatial data must be handled to solve the optimization problem. Future studies will advance the analyses of these multivariate spatial data.

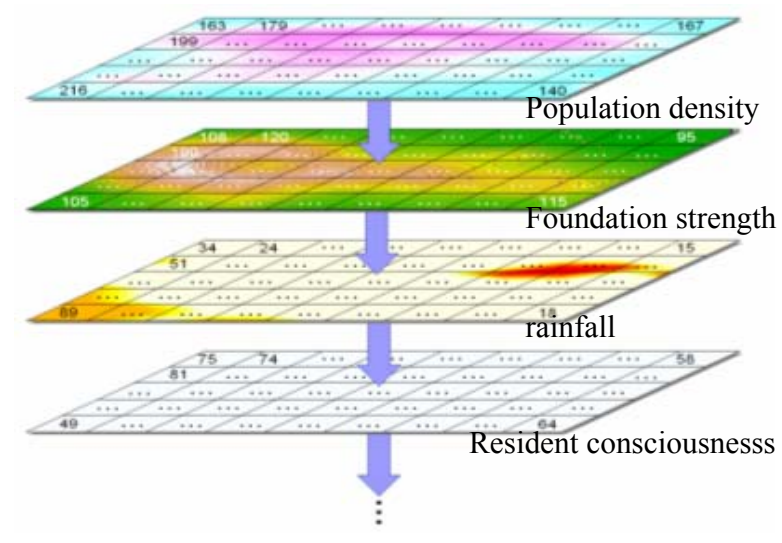

Fig.6 Methodology of optimal location by multivariate spatial analysis.

\section{REFERENCES}

1) Browne, M. W., Cudeck, R. : Alternative ways of assessing model fit. In K. Bollen \& J. S. Long (Eds), Testing structural equation model, pp. 136-162, Newbury Park, CA: Sage, 1993.

2) Chang, N. -B., Shoemaker, C. A., Schuler, R. E. : Solid waste management systems analysis with air pollution and leachate impact limitations, Waste Management \& Research, Vol. 14, pp. 463-481, 1996.

3) Daskalopoulos, E., Badr, O., Probert, S. D. : An integrated approach to municipal solid waste management, Resources, Conservation and Recycling, Vol. 24, pp. 33-50, 1998.

4) Esmali, H. : Facility selection and haul optimization model, Journal of the Sanitary Engineering Division, ASCE, December, pp. 1005-1021, 1972.

5) Helms, B., Clark, R. : Locational models for solid waste mansgement, Journal of Urban Planning and Development Division, ASCE, April, pp. 1-13, 1971.

6) Jacobs, T., Everett, J. W. : Optimal scheduling of landfill operations incorporating recycling, Journal of Environmental Engineering, Vol . 118, No. 3, pp. 420-429, 1992.

7) Lane, W. N., McDonald, R. R. : Land suitability analysis: landfill siting, Journal of Urban Planning and Development, Vol . 109, No. 1, pp. 50-61, 1983.

8) Leão, S., Bishop, I., Evans, D. : Spatial-temporal model for demand and allocation of waste landfills in growing urban regions, Computers, Environment and Urban Systems, Vol . 28, pp. 353-385, 2004.

9) Lober, D. J., Green, D. P. : NIMBY or NIABY: A logit model of public opposition, Journal of Environmental Management, Vol . 40, pp. 101-118, 1994.

10) Lober, D. J. : Resolving the siting impasse: modeling social and environmental locational criteria with a geographic information system, Journal of American Planning Association, Vol . 61, No. 4, pp. 482-495, 1995.

11) Lund, J. : Least-cost scheduling of solid waste recycling, Journal of Environmental Engineering, Vol . 116, pp. 182-197, 1990.

12) Marsh, H. W. : Confirmatory factor analysis models of factorial invariance: A multifaceted approach, Structural Equation Modeling, Vol . 1, pp. 5-34, 1994.

13) McDonald, M. L. : Solid waste management models: a state of the art review, Journal of Solid Waste Technology and Management, Vol . 23, No. 2, pp. 73-83, 1996.

14) Ministry of the Environment : About the state of general waste discharge and disposal (in Japanese), WWW Page, http://www.env.go.jp/recycle/ waste/ippan.html, 2005.

15) Siddiqui, M. Z., Everett, J. W., Vieux, B. E. : Landfill siting using geographic information systems: a demonstration, Journal of Urban Planning and Development, Vol . 122, No. 6, pp. 515-523, 1996.

16) Yuugo ISOBE, Mikio KAWASAKI, Yusaku ONO : Consideration for the improvement of recycling rate by researching of resident consciousness (in Japanese), JSWME $16^{\text {th }}$ Annual Conference, 2005. 